\title{
Prevalence and associated risk factors of depression, anxiety and stress in pregnancy
}

\author{
Kavitha Nagandla $^{1}$, Sivalingam Nalliah ${ }^{1}$, Loh Keng Yin ${ }^{3}$, Zainab Abd Majeed ${ }^{2}$, \\ Mastura Ismail ${ }^{4}$, Siti Zubaidah ${ }^{5}$, Uma Devi Ragavan ${ }^{4}$, \\ Shamini Gayatri Krishnan ${ }^{5}$
}

\author{
${ }^{1}$ Department of Obstetrics and Gynaecology, ${ }^{2}$ Department of Psychiatry, International Medical University, Jalan \\ Rasah, Seremban-70300, Malaysia \\ ${ }^{3}$ Department of Family Medicine, Taylors University, Kuala Lampur, Malaysia \\ ${ }^{4}$ Department of Family Medicine, KK Seremban 2, Malaysia \\ ${ }^{5}$ Department of Family Medicine, KK Seremban, Malaysia
}

Received: 25 May 2016

Accepted: 13 June 2016

*Correspondence:

Dr. Kavitha Nagandla,

E-mail: kavitha.nagandla@gmail.com

Copyright: ( the author(s), publisher and licensee Medip Academy. This is an open-access article distributed under the terms of the Creative Commons Attribution Non-Commercial License, which permits unrestricted non-commercial use, distribution, and reproduction in any medium, provided the original work is properly cited.

\section{ABSTRACT}

Background: Pregnancy is considered as state of emotional well-being. However, pregnancy increases the vulnerability to emotional and psychological conditions such as depression, anxiety, stress and psychoses which have implications to the mother and adverse perinatal outcomes. The objective of this study was to estimate the prevalence and identify the obstetrical and socioeconomic risk factors associated with common mental disorders in the antepartum period by screening and clinical diagnostic interview.

Methods: This was a cross sectional study of pregnant women receiving antenatal care in two antenatal health clinics at Malaysia. Pregnant women were screened twice (16-22 weeks and 34-36 weeks) for common mental disorders by administering depression anxiety and stress scale (DASS-21). A detailed structured questionnaire was used to obtain information on socio-demographic and obstetric characteristics of subjects. Women who screened positive for common mental disorders (DASS 21 scores: depression > 10, anxiety >8, stress >15) were clinically assessed by trained clinician using mini international neuropsychiatric interview (MINI).

Results: Among 288 women screened, the overall prevalence of antenatal depression, anxiety and stress was $23.6 \%$ $(\mathrm{n}=68)$ in the second trimester and $24.7 \%(\mathrm{n}=71)$ in third trimester. The commonest mental health problems are anxiety, $18.8 \%$ depression $6.9 \%$ and stress $4.2 \%$. Diagnostic clinical interview with MINI diagnosed 34\% with adjustment disorder, $23 \%$ with anxiety spectrum conditions (panic and GAD) and $8.5 \%$ major depressive illness. There was no significant difference in developing common mental disorders between second and third trimester $(\mathrm{p}>0.05)$. The socio-demographic factors associated with mental health disorders were low socioeconomic status $(\mathrm{p}<0.02)$, lack of family support $(\mathrm{p}<0.028)$, partner violence $(\mathrm{p}<0.002)$ and obstetrics factors include unplanned pregnancy $(\mathrm{p}<0.01)$.

Conclusions: Anxiety, depression and stress are associated with identifiable socioeconomic and obstetric risk factors.

Keywords: Antenatal, Depression, Anxiety, Stress 


\section{INTRODUCTION}

Pregnancy is considered as state of emotional well-being. However, pregnancy increases the vulnerability to emotional and psychological conditions such as depression, anxiety, stress and psychoses which have implications to the mother and adverse perinatal outcomes. ${ }^{1}$ These conditions are often underdiagnosed, as symptoms being attributed to pregnancy related behavioural changes or undertreated due to concerns of detrimental effects of medications. Besides depression and anxiety, recent parallel literature is emerging in health psychology, social epidemiology supporting the adversity of stress on mothers and infants. ${ }^{2}$ These common mental disorders (CMD) defined as depressive anxiety and stress disorders classified in ICD-10 as "neurotic, stress related and somatoform disorders" and "mood disturbances' appear to be frequent in pregnancy and are important predictors of subsequent postpartum depression. ${ }^{3}$ The combined effects of maternal depression, anxiety and stress in pregnancy are associated with adverse obstetrics outcomes such as preterm labour, preeclampsia and more importantly fetal neurodevelopmental outcomes through a process referred as 'fetal programming'. ${ }^{4}$ Maternal affective disorders activate the maternal hypothalamo-pituitary axis (HPA) and program the fetal hypothalamo-pituitary axis (HPA) axis effecting alterations in the foetus. The effect spans on cognitive and motor development, long term learning and negative reactivity in early years of life manifesting with decreased grey matter density in childhood and impulsivity in adolescents. ${ }^{5}$

Our knowledge so far on negative affective states in pregnancy are essentially symptom based through screening tools. This is largely because of resource constraints to conduct clinical diagnostic interviews to confirm the diagnosis. Nonetheless, pooled information from various studies is informative enough to guide clinician on prenatal screening, early detection and prevention of perinatal mental health disorders. Prenatal care providers have the unique opportunity to address mental health problems in the antenatal period. More than 95\% of pregnant mothers in Malaysia access primary health centres for booking and care of their pregnancies. This affords a window of opportunity to offer screening for mental health disorders and early intervention.

Unfortunately prenatal care providers' show constrains due to lack of information and education in the evaluation and treatment of antenatal mental health disorders. Many obstetricians report that primary training in maternity care has not prepared them to address these important issues of women's mental health. ${ }^{6}$ There is evidence from developing countries that the risk factors of psychiatric disorders in pregnancy are culturally determined. Evidence of stress in pregnancy is shown in certain subgroups of women. ${ }^{7,8}$ Stressors identified among these women include unfavourable employment, low socioeconomic status, intimate partner violence and pregnancy complications. Besides these, risk factors such as maternal childhood abuse, unplanned pregnancy, age, marital status, gravidity, previous history of stillbirth, abortions, past instrumental or operative delivery all contributed to antenatal depression. ${ }^{9}$ Identified risk factors may operate differently during an index pregnancy and in the postpartum as factors such as social support may alter before and after the arrival of a baby. This assumes significance as, if providers know the clinical significance of risk factors for CMD in pregnancy, it provides the access to easily identify the women with highest chances of developing these conditions.

Many studies support that depression and anxiety are the most common psychiatric disorders during pregnancy with an estimated prevalence ranging from 4 to $25 \% .^{10,11}$ The Malaysian national health and morbidity survey (NHMS) reported an increase in prevalence of poor mental health among Malaysian women from $11.2 \%$ to $12.1 \%$ within a decade. ${ }^{12,13}$ There are no firm estimates of perinatal anxiety and no consensus on appropriate screening tools. The prevalence rates are likely to differ among studies and countries due to choice of measures and sociocultural determinants. Studies have used either screening measures or structured interview schedules to confirm the diagnosis.

The objective of our study was to estimate the prevalence and examine risk factors, both obstetrical and socioeconomic, for antepartum common mental disorders both by screening and clinical diagnostic interview at two different trimester's in pregnancy that warrants further prenatal intervention.

The screening tool is the DASS-21 self-administrated questionnaire and is of particular value because it can assess the three dimensions of mental health such as anxiety, depression and stress with good discriminative factor value and high internal consistency (sensitivity of $79.1 \%$, specificity of $77 \%$, internal consistence of 0.88 ) The scale contains three subscales that cover depression (7 items), anxiety (7 items), and stress (7 items). Each item is scored from 0 (at all) to 3 (very much). The total score of each subscale ranged 0-21. Because the DASS21 is short form version of DASS (the long form has 42 items), the final score of each subscale needs to be multiplied by two (x2). The following cut-off score is used to assess the presence of the symptoms: depression $\geq 10$, anxiety $\geq 8$, and stress $\geq 15$. Besides this, DASS 21 scale excludes the somatic symptoms of pregnancy such disturbed sleep, reduced appetite that can be normal in pregnancy. The translated and validated Bahasa Malaysia version of DASS-21 was used in the study. The Bahasa version is validated by Ramli et al and considered to have excellent psychometric properties in Malaysian clinical population. ${ }^{14,15}$ Women who scored above the cut off were further interviewed by consultant psychiatrist using the Mini International Neuropsychiatric Interview (MINI). 
The diagnostic MINI is a brief structured interview for the major axis I psychiatric disorders in diagnostic and statistical manual (DSM) IV and international classification of disease (ICD). ${ }^{10}$ The MINI depression anxiety among pregnant women has a good validity and reliability, and has been translated into many different languages. $^{16}$

\section{METHODS}

Healthcare system in Malaysia operates in the form of dual system consisting of a government-run universal healthcare system and private healthcare system. The ministry of health $(\mathrm{MOH})$ offers a comprehensive range of services through primary care health clinics and hospitals with each primary care health clinic serving 15,000 to 20,000 populations. The staffing includes family medicine specialists, medical officers, public health nurses, pharmacy officers, dentists offering services such as general outpatient care maternal and child care, health promotion and family planning. The health system in Malaysia is considerably centralized and uniform with all the 13 states and 3 federal territories sharing similar organization of health care services protocol including antenatal care. ${ }^{14}$ This study was carried out at two primary health clinics in the state of Seremban, Malaysia over a period of 6 months (March 2014 to August 2014). This study was approved by the ethics committee of the university and registered with the national Malaysian research registry.

The sample of this study was the population included all antenatal women registered in the two primary health clinics from March 2014 to August 2014. They are screened for common mental disorders once at 16-22 weeks and again at 34-36 weeks of pregnancy. The reason for screening them in two trimesters is to assess if the risk status changed over time. Inclusion criteria include all women who are willing to participate and can read and write Bahasa Malaysia/Mandarin and/or english. Exclusion criteria include inability to read and write in Bahasa Malaysia/Mandrin and/or english and with the diagnosis of past history or current diagnosis of psychiatry disorders and who are unwilling to participate. The prevalence rate in Malaysia as studied by Fadzil et al, the prevalence rate would be $10 \%$ and using the confidence interval of $95 \%$, and a precision of $3 \%$, we calculated the sample size of 384 Daniel. ${ }^{15}$ All the study participants were briefed about the study, and informed written consents were obtained.

Data was collected by trained midwife by means of face to face interviews with the socio-demographic and obstetric questionnaire at 16-22 weeks. We obtained standard demographic data including age, marital status, ethnicity, educational level, employment, income, social support including family support and intimate partner violence. The obstetric variables include parity, previous poor pregnancy outcomes (miscarriages, spontaneous or induced abortions, previous caesarean section, obstetric complications such as hypertension and bleeding during pregnancy, preterm birth or low birth weight), and whether the current pregnancy was planned. The complications in the index pregnancy such as anemia, hyperglycemic disorders in pregnancy, hypertension, preeclampsia, placenta previa, preterm labour were extracted from the medical records as documented by the practitioners in the course of prenatal visits. The intimate partner violence information is assessed using abuse assessment screening (AAS) questionnaire that includes the following questions

- Have you ever been emotionally or physically abused by your partner or someone important to you?"

- "During the last year, have you been hit, slapped, kicked or otherwise physically hurt by someone?"

- "Since you have been pregnant, have you been hit, slapped, kicked or otherwise physically hurt by someone?"

- During the last year, has anyone forced you to participate in sexual activities?" (Sexual abuse during last year);

- “Are you afraid of your partner or anyone?" The AAS scoring is based on dichotomous answers (yes/no) to the above questions.

This is followed by administration of the depression, anxiety, and stress-21 questionnaire (DASS 21) screening tool once at 16-22 weeks and again at 34-36 weeks of pregnancy. A brief overview of DASS-21 is provided by the midwife who explained the participants of its intended purpose and method of filling. The participants were informed of confidentiality of the responses. The time taken for the completion of the DASS-21 screening tool was approximately 7-10 minutes. In the presence of positive scores common mental disorders with DASS -21, the women are subjected to diagnostic test with mini international neuropsychiatric interview (MINI) by psychiatrist and further management.

\section{Data analyses}

Data was analyzed with the aid of the software SPSS version 15.0. The association between adjustment disorder and characteristics of the pregnant women was assessed by bivariate and multivariate analyses. We used the Pearson's Chi-square test and the Fisher exact test (when values were less than 5) for comparison of frequencies among groups. Multivariate analysis was performed only with variables with a $\mathrm{P}$ value equal to or less than 0.05 obtained in the bivariate analysis. Odd ratios (OR) and 95\% confidence intervals (CIs) were calculated by logistic regression using the enter method. Statistical significance was set at a $P$ value $<0.05$.

The data obtained were kept highly confidential. Any patient who was detected with severe mental disorder was referred for further psychiatry assessment and management. 


\section{RESULTS}

Among 288 women screened, the overall prevalence of antenatal CMD (depression, anxiety and stress) is $23.6 \%$ $(n=68)$ in the second trimester and in the third trimester of 276 women screened (5 had preterm delivery, $7=$ followed up in home town) the prevalence is $24.7 \%$ $(\mathrm{n}=71)$. Antenatal women in their second trimester have no significant difference in developing common mental disorders compared to third trimester $(\mathrm{p}>0.05)$. The mean gestational age for the mothers with abnormal DASS Score and normal group did not show any significant difference $(p>0.05)$. The commonest mental health problem is anxiety seen in $54(18.8 \%)$ women (Table 1$)$ followed by depression in $20(6.9 \%)$ and stress 12 $(4.2 \%)$. Majority had moderate anxiety $9 \% \quad(n=26)$, followed by moderate depression $3.1 \%(n=9)$ and mild stress $2.1 \%(n=6)$ as shown in Table 2.

Table 1: DASS-21 (depression, anxiety, stress scores of the respondents).

\begin{tabular}{|lll|}
\hline Second trimester (16-22 weeks) & No & $\%$ \\
\hline Normal & 220 & 76.4 \\
\hline Abnormal & 68 & 23.6 \\
\hline Total & $\mathbf{2 8 8}$ & $\mathbf{1 0 0}$ \\
\hline Third trimester (32-36 weeks) & No & $\%$ \\
\hline Normal & 217 & 75.3 \\
\hline Abnormal & 71 & 24.7 \\
\hline Total & $\mathbf{2 8 8}$ & $\mathbf{1 0 0}$ \\
\hline
\end{tabular}

Table 2: Category of DASS-21 (depression, anxiety, stress scores of the respondents).

\begin{tabular}{|lll|}
\hline Anxiety category & No & $\%$ \\
\hline Mild & 17 & 5.9 \\
\hline Moderate & 26 & 9.0 \\
\hline Severe & 11 & 3.8 \\
\hline Total & $\mathbf{5 4}$ & $\mathbf{1 8 . 8}$ \\
\hline Depression category & No & \% \\
\hline Mild & 7 & 2.4 \\
\hline Moderate & 9 & 3.1 \\
\hline Severe & 4 & 1.4 \\
\hline Total & $\mathbf{2 0}$ & $\mathbf{6 . 9}$ \\
\hline Stress category & No & $\mathbf{\%}$ \\
\hline Mild & 6 & 2.1 \\
\hline Moderate & 4 & 1.4 \\
\hline Severe & 2 & 0.7 \\
\hline Total & $\mathbf{1 2}$ & $\mathbf{4 . 2}$ \\
\hline
\end{tabular}

The structured clinical interview for DSM-IV axis I disorders with MINI identified 34\% $\quad(n=45)$ with adjustment disorder, 23\% $(n=30)$ with anxiety spectrum conditions (panic and generalised anxiety disorders) and $8.5 \%(n=2)$ with major depressive illness. Women with moderate anxiety and depression and adjustment were initiated with psychotherapy. Serotonin reuptake inhibitors, SSRI's were initiated when major depression was diagnosed.
Table 3: Socio-demographic data of respondents.

\begin{tabular}{|c|c|c|}
\hline \multicolumn{3}{|l|}{ Age } \\
\hline \multicolumn{3}{|c|}{ Mean age: $28.9 \pm 3.5$} \\
\hline Age group & $\mathbf{n}$ & $\%$ \\
\hline $16-25$ & 56 & 19.4 \\
\hline $26-35$ & 208 & 72.2 \\
\hline$>35$ & 24 & 8.3 \\
\hline Total & 288 & 100.0 \\
\hline \multicolumn{3}{|l|}{ Ethnicity } \\
\hline Malay & 166 & 57.6 \\
\hline Chinese & 61 & 21.2 \\
\hline Indian & 49 & 17.0 \\
\hline Others & 12 & 4.2 \\
\hline Total & 288 & 100.0 \\
\hline \multicolumn{3}{|c|}{ Total household monthly income (RM) } \\
\hline$<500$ & 23 & 8.0 \\
\hline $500-1500$ & 73 & 25.3 \\
\hline $1500-3000$ & 132 & 45.8 \\
\hline $3000-4500$ & 39 & 13.5 \\
\hline$>4500$ & 20 & 6.9 \\
\hline Total & 288 & 100.0 \\
\hline \multicolumn{3}{|c|}{ Education level } \\
\hline Primary & 41 & 14.2 \\
\hline Secondary & 132 & 45.8 \\
\hline Tertiary & 114 & 39.6 \\
\hline Total & 288 & 100.0 \\
\hline \multicolumn{3}{|l|}{ Occupation } \\
\hline Working & 194 & 67.4 \\
\hline Housewife & 92 & 31.9 \\
\hline Total & 288 & 100.0 \\
\hline
\end{tabular}

Table 4: Obstetrics variables.

\begin{tabular}{|c|c|c|}
\hline Pregnancy status & n & $\%$ \\
\hline Planned & 176 & 61.1 \\
\hline Unplanned & 112 & 38.9 \\
\hline \multicolumn{3}{|l|}{ Parity of mothers } \\
\hline Primigravida & 145 & 50.3 \\
\hline Multipara & 143 & 49.7 \\
\hline Pregnancy outcome & $\mathbf{n}$ & $\%$ \\
\hline Normal & 222 & 77.1 \\
\hline Miscarriage & 38 & 13.2 \\
\hline Caesarean & 23 & 8.0 \\
\hline Both caesarean miscarriage & 5 & 1.7 \\
\hline \multicolumn{3}{|l|}{ Family support } \\
\hline Good & 281 & 97.6 \\
\hline Poor & 6 & 2.1 \\
\hline \multicolumn{3}{|l|}{ Husband support } \\
\hline Good & 278 & 96.5 \\
\hline Poor & 10 & 3.5 \\
\hline \multicolumn{3}{|l|}{ Intimate partner violence } \\
\hline Yes & 13 & 4.5 \\
\hline No & 275 & 95.5 \\
\hline
\end{tabular}


Table 3 and 4 summarises the socio-demographic and obstetric characteristics of the participants. The age group of the participants was ranging from 26-35 years old (mean age 28.9+3.5). The majority was Malays, with monthly household income below RM 3,000 per month, married, had completed secondary education and employed. With respect to psychosocial characteristics, majority have good family support with 13 women (4.5\%) reporting intimate partner violence. Half $(50.3 \%)$ were primigravida with $61.1 \%$ having planned pregnancy. The mean gestational age in the second trimester is $18.6+2.5$ weeks and in third trimester is $33.4+2.2$ weeks. Of the 13 women reporting intimate partner violence, three women were diagnosed with adjustment disorders. Of the remaining eight, one was diagnosed with generalised anxiety disorders and one with major depression.

Table 5: Results of bivariate analysis of the sociodemographic characteristics and abnormal DASS scores.

\begin{tabular}{|c|c|c|c|c|}
\hline \multirow{2}{*}{$\begin{array}{l}\text { Socio- } \\
\text { demographic } \\
\text { factors }\end{array}$} & Category & DASS : & ore & \multirow{2}{*}{$P$ value } \\
\hline & \multicolumn{2}{|c|}{ Normal } & Abnormal & \\
\hline \multirow{3}{*}{ Age (years) } & $16-25$ & 44 & 2 & \multirow{3}{*}{0.756} \\
\hline & $26-35$ & 159 & 49 & \\
\hline & $>35$ & 17 & 7 & \\
\hline \multirow{4}{*}{ Ethnicity } & Malay & 131 & 35 & \multirow{4}{*}{0.234} \\
\hline & Chinese & 48 & 13 & \\
\hline & Indian & 34 & 15 & \\
\hline & Others & 7 & 5 & \\
\hline \multirow{5}{*}{$\begin{array}{l}\text { Monthly family } \\
\text { income } \\
\text { (Ringgit } \\
\text { Malaysia) }\end{array}$} & $<500$ & 20 & 3 & \multirow{5}{*}{$0.02 *$} \\
\hline & $500-1500$ & 63 & 10 & \\
\hline & $1500-3000$ & 95 & 37 & \\
\hline & $3000-4500$ & 25 & 14 & \\
\hline & $>4500$ & 17 & 3 & \\
\hline \multirow{3}{*}{ Education level } & Primary & 33 & 9 & \multirow{3}{*}{0.940} \\
\hline & Secondary & 100 & 32 & \\
\hline & Tertiary & 87 & 27 & \\
\hline \multirow{2}{*}{ Occupation } & Working & 154 & 42 & \multirow{2}{*}{0.344} \\
\hline & Housewife & 66 & 26 & \\
\hline
\end{tabular}

\begin{tabular}{|lllll|}
\hline Family support & Good & 218 & 63 & $0.028^{*}$ \\
\cline { 2 - 4 } & Poor & 2 & 4 & \\
\hline $\begin{array}{l}\text { Husband } \\
\text { support }\end{array}$ & Good & 217 & 60 & $0.002^{*}$ \\
\cline { 2 - 4 } & Poor & 3 & 7 & \\
\hline $\begin{array}{l}\text { Intimate partner } \\
\text { violence }\end{array}$ & No & 217 & 55 & $0.001^{*}$ \\
\hline & Yes & 2 & 11 & \\
\hline
\end{tabular}

* Statistical significant at $95 \% \mathrm{CI}$.

The bivariate analyses of association between sociodemographic and obstetrics factors with abnormal DASS scores showed positive association with lower socioeconomic status $(\mathrm{p}<0.02)$, lack of family support $(\mathrm{p}<0.028)$, partner violence $(\mathrm{p}<0.002)$ and unplanned pregnancy $(\mathrm{p}<0.01)$ as shown as in Table 5 and 6 . Outcome of pregnancy and parity were not associated with abnormal DASS score. Multivariate analysis of socio-demographic and obstetrics variables with $\mathrm{P}$ values $<0.05$ obtained by bivariate analysis (Table 7), shows that intimate partner violence and unplanned pregnancy were the two significant risk factors for abnormal DASS score $(\mathrm{p}=0.001)$. In other words, women with history of intimate partner violence have 21 times risk $(\mathrm{OR}=21.7$; 95\% CI: 4.67-100.76, $\mathrm{P}=0.001)$ and those with unplanned pregnancy had 2 times risk $(\mathrm{OR}=1.97, \mathrm{CI}$ : 1.14-3.415, $\mathrm{P}=0.01$ ) of developing $\mathrm{CMD}$ in pregnancy.

Table 6: Results of the bivariate analysis of the obstetrics factors and abnormal DASS scores.

\begin{tabular}{|c|c|c|c|c|}
\hline \multirow{2}{*}{$\begin{array}{l}\text { Obstetrics } \\
\text { factors }\end{array}$} & \multirow{2}{*}{ Category } & \multicolumn{2}{|c|}{ DASS score } & \multirow{2}{*}{$\begin{array}{l}P \\
\text { value }\end{array}$} \\
\hline & & Normal & Abnormal & \\
\hline \multirow{2}{*}{ Pregnancy } & Planned & 143 & 33 & \multirow{2}{*}{$0.01 *$} \\
\hline & Unplanned & 77 & 35 & \\
\hline \multirow{4}{*}{$\begin{array}{l}\text { Outcome of } \\
\text { pregnancy }\end{array}$} & Normal & 175 & 46 & \multirow{4}{*}{0.194} \\
\hline & Miscarriage & 27 & 11 & \\
\hline & Caesarean & 16 & 8 & \\
\hline & $\begin{array}{l}\text { Both } \\
\text { miscarriage } \\
\text { and caesarean }\end{array}$ & n & 0 & \\
\hline \multirow{2}{*}{ Parity } & Primigravida & 116 & 28 & \multirow{2}{*}{0.191} \\
\hline & Multipara & 103 & 40 & \\
\hline
\end{tabular}

Table 7: Multivariate logistic regression for risk factors with abnormal DASS score.

\begin{tabular}{|c|c|c|c|c|c|}
\hline \multirow{2}{*}{ Factors } & & \multicolumn{2}{|c|}{ DASS score } & \multirow{2}{*}{$P$ value $95 \%$ CI } & \multirow{2}{*}{ ODDS ratio/ CI } \\
\hline & & Normal & Abnormal & & \\
\hline \multirow{2}{*}{ Monthly income } & $<\mathrm{RM} 3,000$ & 178 & 50 & \multirow{2}{*}{0.110} & \multirow{2}{*}{$1.441 \mathrm{CI}: 0.756-2.746$} \\
\hline & $>$ RM 3,000 & 42 & 17 & & \\
\hline \multirow{2}{*}{ Family support } & Poor & 2 & 4 & \multirow{2}{*}{0.331} & \multirow{2}{*}{6.9206 CI: $1.2387-38.66$} \\
\hline & Good family support & 218 & 63 & & \\
\hline \multirow{2}{*}{ Husband support } & Poor & 3 & 7 & \multirow{2}{*}{0.778} & \multirow{2}{*}{8.4389 CI: $2.118-33.625$} \\
\hline & Good & 217 & 60 & & \\
\hline \multirow{2}{*}{$\begin{array}{l}\text { Intimate partner } \\
\text { violence }\end{array}$} & YES & 2 & 11 & \multirow{2}{*}{0.001} & \multirow{2}{*}{21.7 CI: 4.67-100.76 } \\
\hline & NO & 217 & 55 & & \\
\hline
\end{tabular}




\section{DISCUSSION}

The prevalence of common mental disorders (CMD) in our study was $23.6 \%$ in the second trimester and $24.7 \%$ in third trimester respectively. Similar studies in Malaysia reported prevalence rate between $8.6 \%-13.8 \% .^{17,18} \mathrm{~A}$ study by Razeeae et al reported similar prevalence among Iranian population using DASS-21 screening tool. ${ }^{19}$ However most of studies report antenatal depression and data on antenatal anxiety disorders are limited. Andersson et al, in his study on point based prevalence of CMD in the second trimester of pregnancy, reported $6.6 \%$ of women with anxiety disorder of which $14 \%$ had underlying psychiatric disorders. The same study reported that only $5 \%$ had sought treatment indicating that antenatal psychiatric disorders are underdiagnosed and under treated. ${ }^{20}$

Fadzil et al observed that gestational age of less than 20 weeks was a significant factor for antenatal anxiety. ${ }^{21}$ In this study, hospital anxiety and depression scale was used and assessment was not compared among the trimesters. The dynamic changes in psychological states at different points in pregnancy are poorly understood. One longitudinal study on the trends of perinatal mental health in pregnancy observed that there anxiety symptoms appeared to be stable throughout pregnancy, with individual variability in the rate of change. However, depression and general stress had a declining trend, which was also variable in the individual rate of change among women during their pregnancy. ${ }^{22}$ One of the strengths of our study was assessment for CMD at two different points in pregnancy. Considering the anticipated increase in anxiety and stress related to nausea, vomiting or hyperemesis gravidarum during the first trimester, we screened for CMD across the second and third trimesters. Our study observed that there was a small increase in CMD in the third trimester compared to second trimester, however this is not statistically significant increase $(p>0.05)$. This may imply that new cases of CMD in pregnancy can occur in any trimester, and a one-time screening may not exclude a probable case of antenatal anxiety or depression. As there is no clear evidence at which point in pregnancy are the CMD are most predictive of postnatal depression, it is paramount for the clinicians to be vigilant of symptoms of CMD that can emerge at different stages of pregnancy and the need for considering on-going screening throughout.

With regard to identification of women at high risk of CMD, there was a positive correlation with lower socioeconomic status $(\mathrm{p}<0.02)$, lack of family support $(\mathrm{p}<0.028)$, intimate partner violence $(\mathrm{p}<0.002)$ and unplanned pregnancy $(\mathrm{p}<0.01)$. However, only intimate partner violence was identified as significant factor in the multivariate analysis. The prevalence of intimate partner violence in our study was $4.5 \%$ which is consistent with local Malaysian study. ${ }^{23}$ The prevalence of intimate partner violence in pregnancy in developed countries is estimated at $4 \%$ to $8 \%$ and studies have shown that prevalence is higher in low and middle income countries. $^{24}$ Evidence from studies shows that domestic violence increases the risk of low birth weight, pre-term labour, miscarriage, fetal death and subsequent child behavioral problems. ${ }^{25}$ The recent UK confidential enquiry into maternal deaths highlighted that domesticviolence-related deaths were perpetrated by both partners and in-laws. ${ }^{26} \mathrm{~A}$ recent systematic review and metaanalysis highlighted the presence of symptoms of all types of perinatal disorders such as depression, anxiety and PTSD among women who experience domestic violence. Further the systemic review observed a two way association between experiences of domestic violence and likelihood of depression in the antenatal and postnatal periods, in which symptoms of depression may increase women's vulnerability to domestic violence, and having experienced domestic violence further increase the odds of depression in the antenatal and postnatal period. $^{27}$ Although the WHO recommend routine screening for domestic violence in pregnancy, the recent Cochrane review found little data on whether screening and other interventions improve outcomes for women experiencing domestic violence in the perinatal period. ${ }^{28}$ However, given the salience of intimate partner violence as risk factor there is need to integrate screening measures into maternal and mental health services to identify domestic violence in the perinatal period and respond appropriately to optimize the maternal and fetal outcome.

The other factors associated with CMD in our study include lower socioeconomic status, lack of family support, and unplanned pregnancy. A Malaysian study observed the prevalence of current depression was as high as $34.5 \%$ and lifetime prevalence of depression was $27.5 \%$ among women with low socio-economic status during pregnancy. ${ }^{29}$

Consistent with the literature, our findings suggest that women in the local context with inadequate social support were at higher risk of developing antenatal and postnatal depression. This relates particularly to support from the partner and parents especially in the postnatal period, considering the need for additional support related to fatigue and mood changes and the demands of caring for the baby. With the increasing trend of nuclear families in Malaysia, the importance of physical and psychological support by the partner cannot be overstated.

The association between unplanned pregnancy and CMD during pregnancy is well documented in the literature. It is estimated in Asia, among 83 million pregnancies each year, $34 \%$ of them are unplanned. It is obvious from these estimates that more than one-third of the pregnant women worldwide do not actually plan to conceive. ${ }^{30}$ The major concern of unplanned pregnancy is its potential effect on women's psychological health and well-being resulting in profound ambivalence and negative emotion that precipitates the development of postpartum depression. ${ }^{31}$ 
The attempt to construct and validate these risk factors is to predict the development of postpartum depression in advance. However, there are no antenatal instruments with diagnostic criteria of obstetrics and biological factors with high positive predictive value for postnatal depression.

From the breakdown of diagnoses with diagnostic interview about $23 \%$ of women met the criteria for an adjustment disorder. Adjustment disorder is a 'constellation of stress-related conditions or significant distress that occurs in response to exposure to a distressing event. ${ }^{32}$ Symptoms are of clinically significant emotional changes that occur in response to a stressor, typically presenting with the symptoms of depression and/or anxiety. The symptoms are usually transient that begins within 3 months of a stressor and ends within 6 months, in the absence of which a more severe underlying disorder may be a possible diagnoses. ${ }^{33}$ There is paucity of information about the epidemiology of adjustment disorders in pregnant women. A Mexican study reported a prevalence rate of $5 \%$, whereas a study from Australia observed a higher prevalence of $36 \%$ in pregnant women. ${ }^{34}$ It is difficult to compare the prevalence of the adjustment disorder found in our study with those found in other studies because there are only few studies in population groups reported in the medical literature. Anxiety disorders were more predominant in our study. Anxiety is gaining more notice recently in maternal health with researcher proposing the need to replace the PND acronym-perinatal depression with PND-A denoting perinatal depression and anxiety. This is attributed to the evidence that pregnancy anxiety predicts the risks of preterm labour with meaningful effects sizes that are larger than the known risk factors such as smoking. ${ }^{35}$

Several limitations are noted in this study. We have not done randomization and the selection bias was one of the potential limitations in our study. Sampling bias might have occurred in this study as the subjects were recruited using convenience sampling at two pubic primary care health centers; this may be not be the actual representation of the entire population. Nevertheless, considering the antenatal care in Malaysia is shared care between primary health clinics and hospital, this community-based sample is likely to be indicative of the situation among the women accessing the services at the primary care clinics. Again caution is required in interpretation of the data as the cross sectional nature of the study (although assessments was done at two points in pregnancy,) could not tell about the causal relationship of the variables, except correlation. Besides that, additional important variables were not controlled for, including previous infertility, complications during pregnancy such as diabetes, hypertension, preeclampsia, antepartum haemorrhage, gynaecological morbidities and previous infertility. These variables may over- or underreport the prevalence of CMD. As for reporting on intimate partner violence is concerned, it is possible that women may not have reported considering its sensitive nature.

Our results highlight several important correlates of CMD during pregnancy such as lack of social support, domestic violence and unplanned pregnancy. Intimate partner violence continued to be associated with antepartum depressive symptoms in multivariate analyses as evidenced by literature. Assessment for CMD at two different points in pregnancy has provided an important step in understanding the dynamic nature of anxiety and depression across different stages of pregnancy. Our results indicate that detection of women at risk of developing postnatal depression can be done in early pregnancy. Further, the accuracy of the prevalence in our study was improved by follow up with clinical diagnostic interview. Importantly our study identified the need for clinical attention to perinatal anxiety disorders that have seemingly emerged as a more prevalent and potent risk factor for adverse maternal and fetal outcomes. Our results are important for practicing clinicians as they identify risk factors during routine obstetric care. The providers should consider the possibility of antenatal patients developing depression and anxiety symptoms in the presence of risk factors. This window of opportunity should be our best bet in reducing postnatal depression. The antenatal records should have remainder boxes for history of CMD and intimate partner violence. Future research should focus on capturing this data and evaluate how to use these risk factors to improve our screening accuracy and clinical assessments.

\section{ACKNOWLEDGMENTS}

The authors would like to acknowledge the small grant awarded for this study by the Joint Committee of Ethics and Research, International Medical University ( Project No: 290/2013). We are Hereby; many thanks go to International Medical University, Malaysia for supporting this study. The authors are grateful to the healthcare providers of primary health care clinics, Seremban and all mothers who volunteered to be included in the study. We are thankful to the Ministry of Health, Malaysia for their permission to conduct the study (NMRR: 13-141518474).

\section{Funding: No funding sources Conflict of interest: None declared \\ Ethical approval: The study was approved by the Institutional Ethics Committee}

\section{REFERENCES}

1. Diana C, Xanthoula K. Psychiatric disorders in pregnancy. BCMJ. 2005;47(2):96-9.

2. Schetter CD, Tanner L. Anxiety, depression and stress in pregnancy: implications for mothers, children, research, and practice. Curr Opin Psychiatry. 2012;25(2):141-8. 
3. Patel V, Kleinman A. Poverty and common mental disorders in developing countries. Bull WHO. 2003;81:609-15.

4. Kaplan LA, Evans L, Monk C. Effects of mothers' prenatal psychiatric status and postnatal caregiving on infant bio behavioral regulation: Can prenatal programming be modified? Early Hum Dev. 2007;84(4):249-56.

5. Buss C, Davis EP, Muftuler T. High pregnancy anxiety during midgestation is associated with decreased gray matter density in 6-9 year old children. Psychoneuroendocrinology. 2010;35:14153.

6. Byatt N, Biebel K, Friedman L, Debordes-Jackson G, Ziedonis D, Pbert L. Patient, provider and systemlevel barriers and facilitators to addressing perinatal depression. J Reprod Infant Psychol. 2012;30(5):436-9.

7. Borders AEB, Grobman WA, Amsden LB, Holl JL. Chronic stress and low birth weight neonates in a low-income population of women. Obstet Gynecol. 2007;109:331-8.

8. Giscombé CL, Lobel M. Explaining disproportionately high rates of adverse birth outcomes among African Americans: the impact of stress, racism, and related factors in pregnancy. Psychol Bull. 2005;131:662-83.

9. Andria S, Maggie S, Martina RL. Obstetric care providers are able to assess psychosocial risks, identify and refer high-risk pregnant women: validation of a short assessment tool. BMC Pregnancy and Childbirth. 2015;15:41.

10. Rich-Edwards JW, Kleinman K, Abrams A, Harlow BL, McLaughlin TJ, Joffe H. Socio-demographic predictors of antenatal and postpartum depressive symptoms among women in a medical group practice. J Epidemiol Community Health. 2006;60:221-7.

11. Pereira PK, Lovisi GM, Pilowsky DL, Lima LA, Legay LF. Depression during pregnancy: prevalence and risk factors among women attending a public health clinic in Rio de Janeiro, Brazil. Cad Saude Publica. 2009;25:2725-36.

12. Institute of Public Health. The second national health and morbidity survey 1996 (NHMS II): Kuala Lumpur: Ministry of Health Malaysia; 1999.

13. Institute of Public Health. The third national health and morbidity survey (NHMS III): 2006. Kuala Lumpur: Ministry of Health Malaysia; 2008.

14. Jaafar S, Mohd Noh K, Abdul Muttalib K, Othman NH, Healy J. Malaysia Health System Review Geneva: WHO; 2013.

15. Musa R, Fadzil MA. Translation, validation and psychometric properties of Bahasa Malaysia version of the depression anxiety and stress scales (DASS) ASEAN Journal of Psychiatry. 2007;82(2):82-9.

16. Sheehan DV, Lecrubier $Y$, Harnett-Sheehan K, Amorim P, Janavs J, Weiller E, et al. The MINI international neuropsychiatric interview (MINI): the development and validation of a structured diagnostic psychiatric interview. J Clin Psychiatry. 1998;59(20):22-33.

17. Ali NS, Azam IS, Ali BS, Tabbusum G, Moin SS. Frequency and associated factors for anxiety and depression in pregnant women: a hospital-based cross-sectional study. Scientific World Journal. 2012;2012:653098.

18. Matthey S, Ross-Hamid C. The validity of DSM symptoms for depression and anxiety disorders during pregnancy. J Affect Disord. 2011;133(3):54652.

19. Razieh R, Mahbobeh F. Predictors of mental health during pregnancy. Iran J Nurs Midwifery Res. 2014;19(7 Suppl1):S45-S50.

20. Andersson L, Sundstrom-Poromaa I, Bixo M, Wulff M, Bondestam K, Astrom M. Point prevalence of psychiatric disorders during the second trimester of pregnancy: a population-based study. Am J Obstet Gynecol. 2003;189:148-54.

21. Fadzil A, Balakrishnan K, Razali R, Sidi H, Malapan $\mathrm{T}$, Japaraj RP, et al. Risk factors for depression and anxiety among pregnant women in hospital Tuanku Bainun, Ipoh, Malaysia. Asia-Pacific Psychiatry. 2013;5:7-13.

22. Heron J, O'Connor TG, Evans J, Golding J, Glover $\mathrm{V}$. The course of anxiety and depression through pregnancy and the postpartum in a community sample. J Affect Disord. 2004;80(1):65-73.

23. Othman S, Adenan NM. Domestic violence management in Malaysia: a survey on the primary health care providers. Asia Pacific Family Medicine 2008;7:2.

24. Devries KM, Kishor S, Johnson H, Stöckl H, Bacchus LJ. Intimate partner violence during pregnancy: analysis of prevalence data from 19 countries. reprod health matters. 2010;18:158-70.

25. Flach C, Leese M, Heron J, Evans J, Feder G. Antenatal domestic violence, maternal mental health and subsequent child behaviour: a cohort study. BJOG. 2011;118:1383-91.

26. Lewis G. Confidential enquiry into maternal and child health: saving mothers' lives. London: Centre for Maternal and Child Enquiries; 2011.

27. Oram S, Galley H, Trevillion K, Feder G, Louise M. Howard: domestic violence and perinatal mental disorders: a systematic review and meta-analysis. PLoS Med. 2013;10(5):e1001452.

28. Priest S, Austin M, Sullivan E. Antenatal psychosocial screening for prevention of antenatal and postnatal anxiety and depression (protocol). The Cochrane Database of Systematic Reviews. 2005;(1):CD005124.

29. Omar Din M, Mohd Noor N. Prevalence and factors associated with depressive symptoms in Malay women. Women and Health. 2009;49:573-91.

30. Racherla SJ. Addressing unplanned pregnancies can reduce pregnancy and childbirth related deaths. 2006;12(2): 12 .

31. Cigoli V, Gilli G, Saita E. Relational factors in psychopathological responses to childbirth. Journal 
of Psychosomatic Obstetrics and Gynecology. 2006;27(2):91-7.

32. Akutsu PD, Abhari B. Adjustment disorders in Asians and Asian Americans. Asian J Psychiatr. 2014;7(1):68-70.

33. Katzman J, Geppert C. Adjustment disorders. In: Sadock B, Sadock V, Ruiz P, editors. Kaplan and sadock's comprehensive textbook of psychiatry. $9^{\text {th }}$ ed. Vol. 2. Philadelphia: Lippincott Williams and Wilkins; 2009:2187-2196.

34. Alvarado-Esquivel CA, Sifuentes-Alvarez A, SalasMartinez C. Adjustment disorder in pregnant women: prevalence and correlates in a Northern Mexican City. J Clin Med Res. 2015;7(10):775-80.

35. Matthey S. Detection and treatment of postnatal depression (perinatal depression or anxiety). Current Opinion in Psychiatry. 2004;17:21-9.

Cite this article as: Nagandla K, Nalliah S, Yin LK, Majeed ZA, Ismail M, Zubaidah S, et al. Prevalence and associated risk factors of depression, anxiety and stress in pregnancy. Int J Reprod Contracept Obstet Gynecol 2016;5:2380-8. 